\title{
Rain-Rate Estimate Algorithm Evaluation and Rainfall Characterization in Tropical Environments Using 2DVD, Rain Gauges and TRMM data
}

\author{
Margarita Baquero ${ }^{1}$, Sandra Cruz-Pol ${ }^{1}$, Senior Member, V. N. Bringi ${ }^{2}$ and V. Chandrasekar ${ }^{2}$ \\ ${ }^{1}$ University of Puerto Rico - Mayagüez, ${ }^{2}$ Colorado State University
}

\begin{abstract}
Precipitation is an important environmental parameter which affects the hydrology of the land surface, coastal processes, terrain stability, and climate and global heat circulation. Understanding rainfall distribution and intensity can improve protection of environmental and human resources, and knowledge of geophysical process of land, ocean and atmosphere. Rain measurements have been historically verified using traditional rain-gauges in high detail or microwave radars that cover vast areas. Nevertheless, in order to develop more accurate rainfall forecast algorithms and validate them, the drop size distribution (DSD) of rainfall events need to be studied. Using measurements from NASA TRMM satellite and rain gauges, the raindrop size distribution will be studied and used in analyzing disdrometer rain retrieval. The comparison took place on September $15^{\text {th }}$ to $17^{\text {th }}, 2004$ in San Juan, Puerto Rico; when the tropical storm Jeanne passed by the island of Puerto Rico, in the Caribbean.

Only 4 out of 21 locations worldwide where 2DVDs have been deployed in the past are in the tropics, therefore we expect this work to provide further insight into the rainfall statistics of tropical regions.
\end{abstract}

\section{INTRODUCTION}

The quantitative estimation of rainfall rates using meteorological radar has been one of the main research topics in radar meteorology and radar hydrology. The relationship between rain rate $R$ and the radar reflectivity factor $Z$ (Z-R relations) have been widely used to estimate rainfall amounts. However, it is commonly recognized that this classical rain estimation method has many sources of error. One of them is the sensitivity of Z-R relations with respect to variations in raindrop size distributions (DSD). [1]

For shorter wavelengths in comparison with S-band, such as $\mathrm{X}$-band $(3 \mathrm{~cm})$ and $\mathrm{C}$-Band $(5 \mathrm{~cm})$, attenuation by rainfall is an additional source of error for quantitative rainfall estimation [2]. The raindrop distribution is generally assumed to be uniform within the radar sampling volume; however, gradients within the sampling volume can cause overestimation or underestimation of rain rates. Contamination of hail and the bright band is one of the wellknown sources of bias error. To infer intrinsic meteorological parameters from the measurement in X-Band, accurate correction for attenuation is critical [1].
Recently, polarimetric radar techniques have been evolving quickly and its achievements have become a center of attention. In contrast to conventional radars, which use Z-R relations to estimate rain rates, polarimetric radar use both $Z$ and polarimetric variable information such as specific differential phase $K_{d p}$ and/or differential reflectivity $\mathrm{Z}_{\mathrm{dr}}$. Seliga and Bringi (1976)[3] showed that $Z_{d r}$ could be used to retrieve rain drop size distributions and to improve rain rate estimations was proposed theoretically (e.g., Oguchi and Hosoya 1974 [4], and Seliga and Bringi [3]) and now is recognized as an essential parameter for polarimetric radar measurements. Comparisons of radar rain rate estimates with gauge measurements have often been performed to asses the accuracy of radar rate rain estimators. Matrosov et al. (2002) [5] showed that case tuned $R(Z)$ was a more accurate estimator than $R\left(K_{d p}\right)$ by comparing the X-band polarimetric radar estimates with gauges measurements.

A radar calibration method that has been widely used in operations employs radar-rain gauge comparison. It is referred to as the adjustment rather than a calibration. In the simpler version of the method, observed radar reflectivities are transformed into rainfall rates, using a single or several R-Z relationships $Z=a R^{b}$, and these rates are compared to rainfall rates observed by one or several rain gauges.

Quantitative Precipitation Estimation (QPE) pursues to improve the precipitation estimates and enhance the reliability of flood prediction. Developing low cost radar is one of the key goals of this research enterprise. This can be accomplished by moving to higher frequencies, specifically $\mathrm{X}$-Band [6].

In order to evaluate the currently used algorithms for rain estimation, we performed a data comparison and correlation between NCDC rain gauges, NWS rain gauge, a 2DVD and NASA TRMM. Furthermore, this will help in the characterization of this tropical island's rainfall rate statistics and its regional variations. The results of this work will present important information for QPE algorithms for enhanced rainfall estimations, much needed for the tropical zones communities.

\section{EQUIPMENT DESCRIPTION}




\section{A. Rain Gauge NCDC.}

The rain gauge existing in San Juan (Puerto Rico) is of an

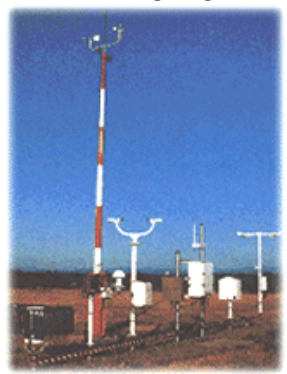

Automated Surface Observing System (ASOS) type with an ATIS interface, which can be seen in Fig.1. Such an interface allows ASOS weather observations to be appended to the ATIS broadcast, thereby providing real-time weather when the tower is closed.

Figure 1 ASOS-ATIS

Upon closing part-time towers in the evening, the controller will have the ability to add overnight ATIS information to the ASOS automated voice weather message. When the tower is open the pilots will get ATIS information and the hourly weather. When the tower is closed, the pilots will get the one-minute weather information along with the ATIS information on the same frequency. This approach allows the pilot to utilize the same frequency 24 hours a day to obtain weather information.

An ASOS processes and outputs cloud height/condition temperature, dew point, barometric pressure, density altitude, wind speed, wind direction, and gusts plus a freezing rain sensor and thunderstorm reporting [7] [8].

\section{B. TRMM}

Tropical Rain Measurement Mission (TRMM) is the first space-borne precipitation radar (PR) designed to provide three-dimensional maps of storm structure. It was launched on November 28, 1997. Its circular orbit altitude is $350 \mathrm{~km}$ with 35 deg. of inclination. It has an orbit duration of 91 minutes (16 Orbits a day), spending 1.14 minutes over Puerto Rico during each orbit and 18.2 minutes each day [9].

The TOVAS website provides TRMM data in text format in addition to rain rate pictures, as shown in Fig. 2.

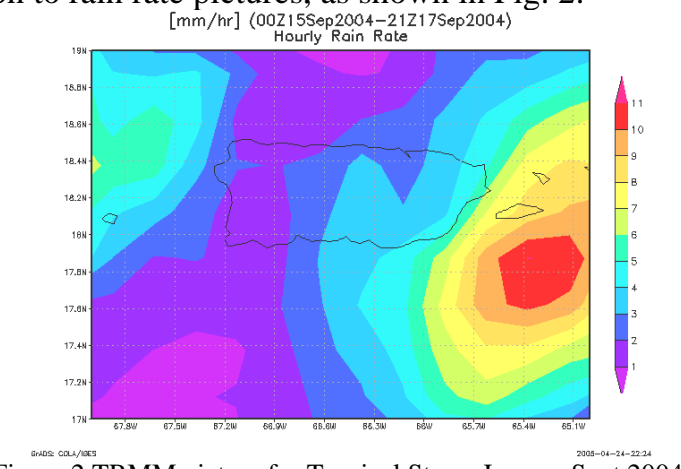

Figure 2 TRMM picture for Tropical Storm Jeanne, Sept 2004.

\section{C. $2 D V D$}

A 2-dimensional video disdrometer (2DVD) records orthogonal image projections of raindrops as they cross its sensing area, and can provide a wealth of information, including velocity and shape, of individual raindrops. The 2DVD permits in principle at least, measurement of rain, snow and mixed precipitation [10].

\section{DATA COMPARISON AND ANALYSIS}

\section{A. TRMM Location Computation.}

In order to compare 2DVD data with the one from TRMM, an area over the 2DVD's position is needed to take data from TRMM. By using the circular orbit attitude $(r=350 \mathrm{~km}$, TRMM $\theta=0.25$ degrees) approximating to a triangle, as in (1), the edge $s$ of the triangle is calculated, which defines the area to be taken from TRMM, as it can be seen in Fig. 3 .

$$
s=r \tan (\theta)
$$

Notice that $s$ values are typically given in $\mathrm{km}$, but localization data in TRMM's website is available in degrees, so conversion between them is required. Using that value in degrees and knowing 2DVD's position (latitude $=18.26$, longitude $=-66.00$ ), the area where data should be taken is then easily obtained, as shown in Figure 3.

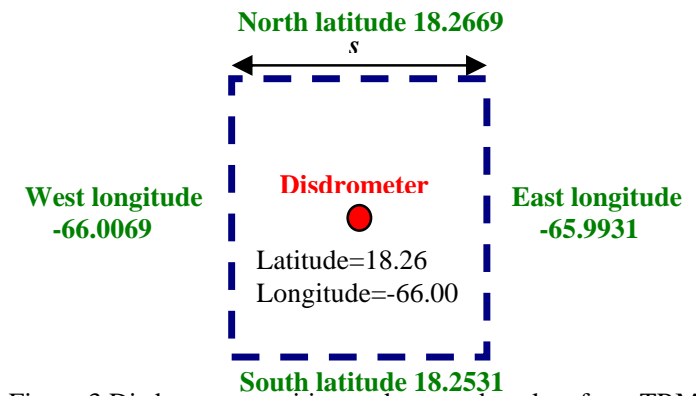

Figure 3 Disdrometer position and area to be taken from TRMM

\section{B. Data Comparison per Hour}

With the goal of comparing 2DVD data with each one of the other devices (TRMM and NCDC), separate analyses were made, comparing TRMM against 2DVD and NCDC against 2DVD. The comparison took place with data collected from September $15^{\text {th }}$ to $17^{\text {th }}, 2004$, dates in which the tropical storm Jeanne passed by Puerto Rico. The root-mean-squared (RMS) error was computed for each case.

1) Hourly Data comparison Disdrometer-TRMM

Since the TRMM data from NASA TOVAS is averaged every 3 hours and 2DVD is obtained every minute, we computed the rain rate per hour for 2DVD data and average rain rate per hour for TRMM data, as shown in Fig. 4 for September 15 and 16 of 2004. Tropical storm Jeanne passed closer to the area on the $15^{\text {th }}$. Notice that TRMM data tends to overestimate the rain rate; this is probably due to the averaging of areas where the rain was stronger, whereas the disdrometer is measuring only at one point. 


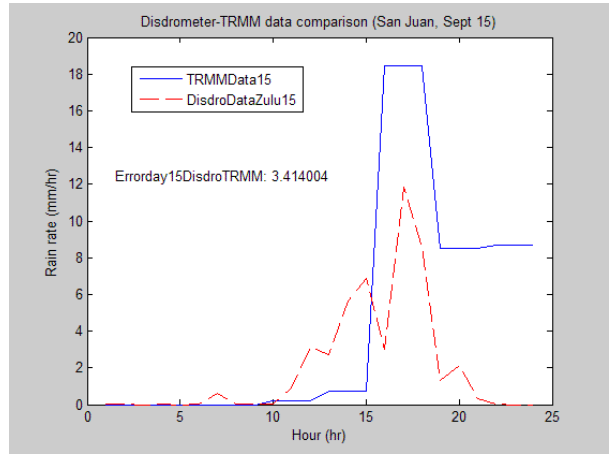

(a)

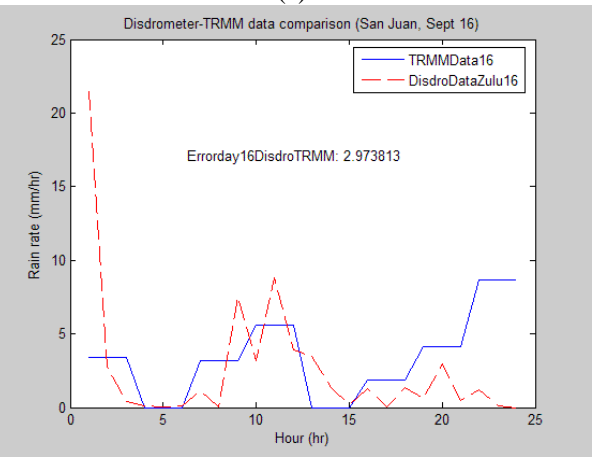

(b)

Figure 4 Disdrometer-TRMM data comparison in San Juan for (a) Sept $15^{\text {th }}$ and (b) Sept $16^{\text {th }} 2004$

\section{2) Hourly Data comparison Disdrometer-NCDC}

To co-locate in time (local AST time), 4 hours were subtracted from the original 2DVD data, which is given in UT. NCDC rain gauges, measured in inches, were changed to millimeters, before comparing it to disdrometer data. As shown in Fig. 5, disdrometer and rain gauge data compares very well.

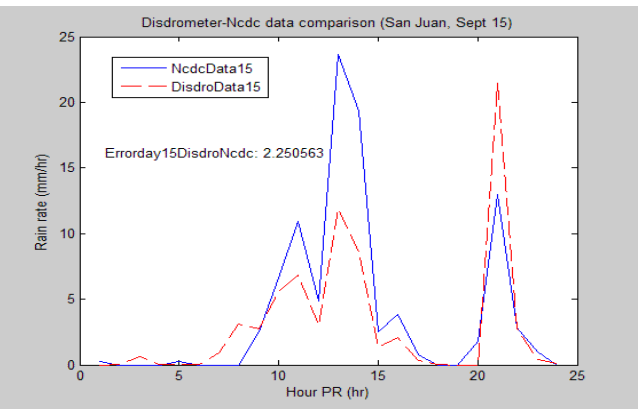

(a)

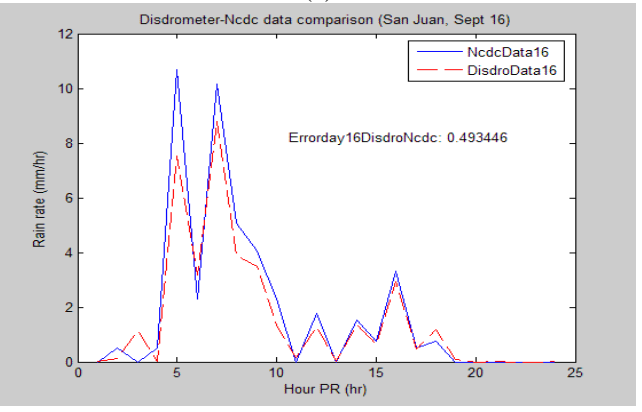

(b)

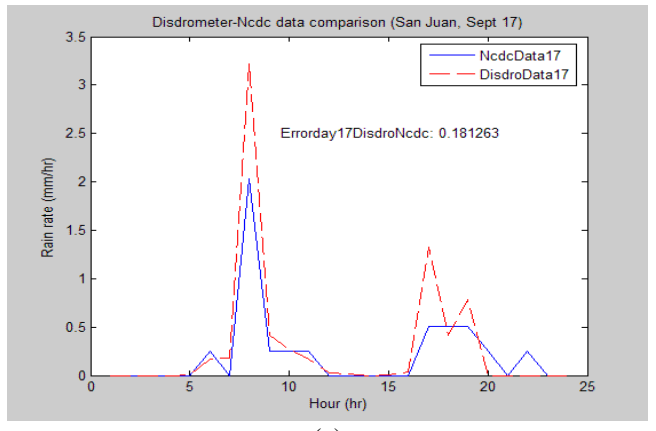

(c)

Figure 5 Disdrometer-NCDC data comparison for (a) Sept $15^{\text {th }}$, (b) Sept $16^{\text {th }}$ and (c) Sept $17^{\text {th }} 2004$.

\section{Cumulative data comparison}

Cumulative rain rate was also computed for each day, for each sensor, as shown in Fig. 6. During the storm on Sept $15^{\text {th }}$, the disdrometer shows about half the accumulated rainfall than both, the rain gauge and the TRMM estimate.

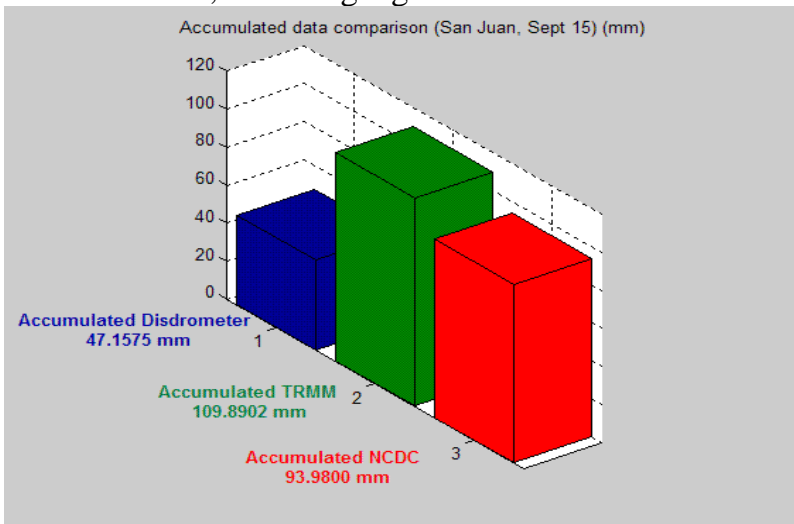

Figure 6 Disdrometer-TRMM-NCDC cumulative data comparison (San Juan, Sept 15)

Another rain gauge utilized for comparison purposes was one maintained by the National Weather Service (NWS), located very close to the 2DVD. Fig 7 compares such rain gauge against the other devices for Sept $16^{\text {th }}$. This data was not available for the $15^{\text {th }}$.

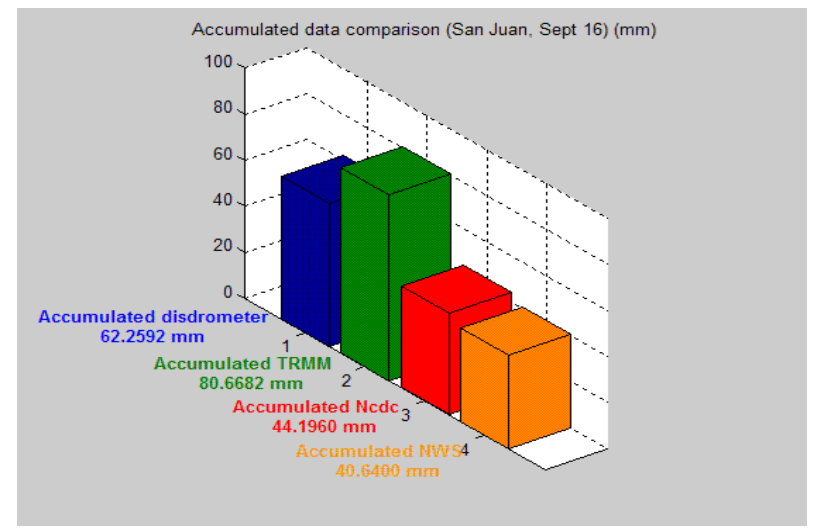

Figure 7 Disdrometer-TRMM-NCDC-Rain gauge NWS cumulative data comparison (San Juan, Sept 16) 


\section{Rainfall Algorithm at the X-band}

This Rainfall algorithm was derived from disdrometer data collected during September 16th, 2004, dates in which the tropical storm Jeanne passed by Puerto Rico.

The criteria to distinguish between convective and stratiform rain is typically defined as $R>0.5 \mathrm{~mm} / \mathrm{hr}$ with a standard deviation $<1.5 \mathrm{~mm} / \mathrm{hr}$ for the latter, whereas convective rain requires $R>5 \mathrm{~mm} / \mathrm{hr}$ with a standard deviation $>1.5 / \mathrm{hr}$.

A simulation of X-band polarimetric radar was performed to examine the expected response in the upcoming CASA radar network testbed on the island. This simulation provides the following parameters: $Z_{h h}(\mathrm{~dB}), Z_{d r}(\mathrm{~dB}), K_{d p}($ degree $/ \mathrm{km}), A_{h}$ (specific attenuation, $\mathrm{dB} / \mathrm{km}), A_{h v}(\mathrm{~dB} / \mathrm{km})$ and several other polarimetric parameters.

Next, simulated-radar and disdrometer data were used in order to compute a $R\left(Z_{h}\right)$ [11] relation for convective and stratiform rain, as it is shown in Fig.8.

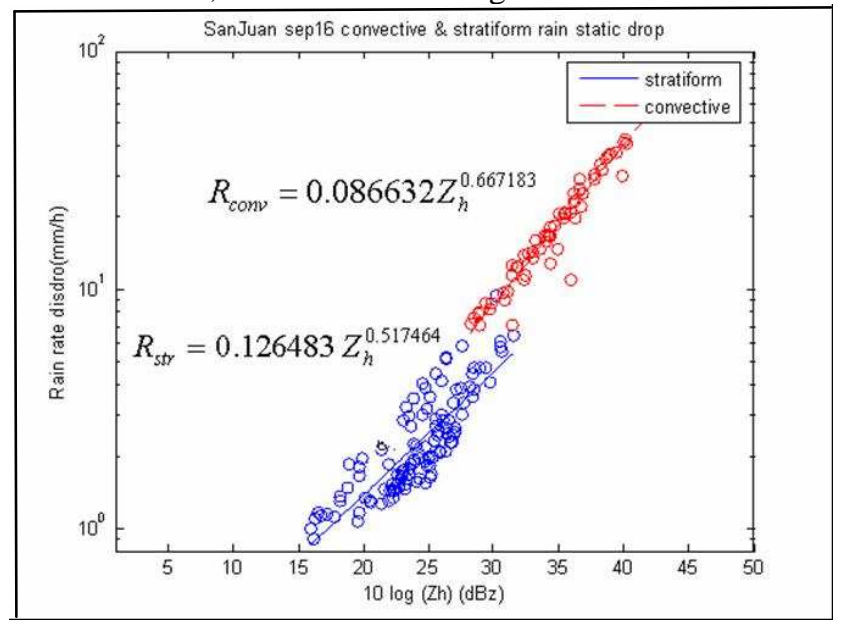

Figure 8 Derived coefficients for the R-Z algorithms in X-band for convective and stratiform rain during the T.S. Jeanne pass over the tropical island of Puerto Rico, Sept 2004.

\section{CONCLUSIONS}

Data from NCDC and NWS rain gauges compared very well to that of the disdrometer. TRMM data was slightly higher, but this can be due to its low spatial-temporal resolution. Nevertheless, there was agreement in peak values of rainrates versus time in all the devices.

The RMS error comparing NCDC against 2DVD was significantly smaller than comparing against TRMM, which reveals a greater similarity between NCDC and 2DVD data than for TRMM.

The derived coefficient $\alpha$ for the R-Z algorithms, $R=\alpha Z^{\beta}$,in $\mathrm{X}$-band for convective and stratiform rain during the T.S. Jeanne, is approximately double of that found in Australia during the wet season [1]. Yet, the $\beta$ coefficient is similar to those of that study (Fig. 8). This may be due to the sensitivity to variations in DSD and to the nature of the event, in this case, storm-level rain. Furthermore, the Matlab application developed to perform this comparison might serve as a tool for comparing any data related to rain phenomena.

\section{FUTURE WORK}

For future work, we intend to simulate the behavior of a $10 \mathrm{GHz}$ radar with data from the disdrometer for stratiform and convective rain, and each one for oscillating and static drops.

The main goal will be coming up with different equations enabling rain rate calculations from radar measurements of $Z_{d r}, K_{d p}$ and $Z_{h}$. Upon installment of CASA radars, the required calibration will be made by comparing 2DVD, TRMM and NCDC data through the programs developed along with the present work.

\section{ACKNOWLEDMENTS}

This work is partially funded by the Collaborative Adaptive Sensing of the Atmosphere (CASA) Engineering Research Center (NSF AN0313747), and by the NASA Tropical Center for Earth Studies (TCESS- NCC5-518).

\section{REFERENCES}

[1] Masayuki Maki and V.N.Bringi, 2004:Effect of natural Variations in Rain Drop size Distributions on Rain Rate Estimators of $3 \mathrm{~cm}$ Wavelength Polarimetric Radar. J. Meteor. Soc.Japan.

[2] Battan,L.J., 1973:Radar observation of the atmosphere. Univ.Chicago Press, 324 pp.

[3] Seliga T.A. and V.N.Bringi,1976:Potencial use of radar differential reflectivity measurements at orthogonal polarizations for measuring precipitation. J. Appl Meteor., 15, 69-76.

[4] Oguchi,T and Y.Hosoya, 1974:Differential attenuation and differential phase shift of radio waves due to rain:Calculationsof microwave and millimeter wave regions. J. Rech. Atmos., 8, 121128.

[5] Matrosov,S.Y., K.A. Clark, B.E. Martner, and A. Today, 2002:Xband polarimetric radar measurements of rainfall. J. Appl. Meteor., 41, 941-952.

[6] Collaborative Adaptive Sensing of the Atmosphere (CASA) Engineering Research Center, "Overview" [Online]. Available from http://www.casa.umass.edu.

[7] Federal Aviation Administration [Online]. Available from http://faa.gov/asos/,

[8] National Climate data center [Online]. Available from http://www.ncdc.noaa.gov/servlets/ULCD

[9] TRMM Online Visualization and Analysis System (TOVAS) [Online]. Available from http://lake.nascom.nasa.gov/tovas/3B42RT/index2.shtml

[10] Kruger, A., W.F. Krajewski, “Two-Dimensional Video Disdrometer: A description", Journal of Atmospheric and Oceanic Technology, Vol. 19, pp. 602-617, 2001. 
[11] Bringi, V.N. and V.Chandrasekar, 2001:Poalrimetric Doppler weather radar. Cambridge Univ. Press, 636 pp. 